\title{
Exploring the Spatial Distribution and Regional Differences of Obstetric Complications Across India: Evidence-Based on NFHS- 4: 2015-16.
}

Shriya Bajaj ( $\sim$ shriya03bajaj@gmail.com )

International Institute for Population Sciences

Rahul Jha

International Institute for Population Sciences

\section{Research Article}

Keywords: Maternal, complications, spatial, morbidity, India

Posted Date: July 6th, 2021

DOI: https://doi.org/10.21203/rs.3.rs-646271/v1

License: () (7) This work is licensed under a Creative Commons Attribution 4.0 International License. Read Full License 


\section{Abstract}

Background: In recent years, obstetric complications have increased among pregnant women, which leads to disease burden among them in the later stages of life and sometimes resulting in deaths after birth. The spatial research helps to know the pattern and trait at a regional level, and accordingly, the interventions can take place in terms of health care services.

Method: The study is based on National Family Health Survey-4 (NFHS-4) conducted in India in the year 2015-16. This study focused on ever-married women aged 15-49 years who have delivered at least once during the five years preceding the survey. GeoDa was used to generate local indicators of spatial association (LISA) significance and cluster maps and Moran Index. It measured the correlation among neighbouring observations in a pattern and the levels of spatial clustering among neighbouring.

Results: The regions identified under different pregnancy complications were different. The pregnancy complications during pregnancy and after pregnancy were high in India's Northern and Eastern provinces. While complication during delivery was high in Northern and Southern India. The local spatial autocorrelation showed that the high-high regions of the pregnancy complication were located in the low prevalence regions (high-low).

Conclusion: Despite several programmes and policies for pregnant women the obstetric complications still exist in several pockets of India. The spatial analysis gives us insights to provide special attention to specific regions; the pregnancy complication is one of the main reasons for higher maternal mortality.

\section{Background}

Reproductive morbidities basically include gynaecological and obstetric morbidities. An obstetric morbid complication has been defined as the acute condition arising from maternal deaths such as antepartum or postpartum haemorrhage, obstructed labour, postpartum sepsis, complications of abortion, preeclampsia or eclampsia, ectopic pregnancy, and ruptured uterus, or indirect causes such as anaemia, malaria, and tuberculosis (Maine, 1997). Obstetric morbidity is an important marker for obstetric care (Paruk, 2001).

Three decades back World Health Organization, (WHO) at the International Conference in Kenya in order to improve the quality of maternal health worldwide declared the Safe Motherhood Initiative in 1987. The initiative focused mainly on the low and middle-income countries as $98 \%$ of the maternal deaths occurred in low-income countries (Santora, 2020). The low-income countries even today have a high maternal mortality ratio of 462 per thousand live births (WHO, World Health Organization, 2019). Maternal mortality is unacceptably still high, the Sustainable Development Goals given by the United Nations have been set to achieve a maternal mortality ratio of less than 70 per 100,000 live births by 2030 (Assembly, 2015).

Daily 800 women die worldwide due to complications from childbirth, the main cause of deaths in developing nations have been severe bleeding, hypertension, sepsis, unsafe abortion, and obstructed labour (Spiegel, 2013). The World Health Organisation (WHO, 2012) stated that about 15\% of pregnant women develop a life-threatening complication out of which few require major intervention all of which require a great medical skill. In developing countries, $6.25 \%$ of pregnant women may die of pregnancy-related complications (WHO, 2004). Studies have shown that women in developing countries face a high risk of developing life-threatening complications for them as well as their new-borns (Filippi, 2010). There is still very little understood about the impact of socioeconomic and demographic factors on pregnancy-related complications. Education, religion, ANC care and other socio-economic characteristics, although poorly explained, were found to have an impact on various complications (Gogoi M. U., 2014). There is a little and unexplored interrelationship of different pregnancy-related complications understanding about the impact of one complication on another.

India has improved in the last few decades, the maternal mortality ratio has reduced from 212 in 2007-08 to 113 in 2016-18 (SRS, 2020). In India still today, obstetric morbidities have not been given much importance. The women even after being aware of the darker side of pregnancy complications resulting in deaths many times ignore it. In India, maternity-related complications are the leading cause of death and disability among women of reproductive age (Biswas, 2016). The complications are a result of inadequate facilities for identifying and managing complications, as most of them are preventable (World Bank, 1996). The frequency of obstetric morbidity depends on the area and available health care services (Prual, 2000). In developing countries like India, where pregnant women are at high risk of morbidity and mortality resulting from different psychological stress, which remains as high as 10 to 20 percent in developing countries like India (Quraishi, 2017). A study conducted in rural Gambia reported that obstetric morbidities such as anaemia, obstructed labour, haemorrhage and eclampsia were the main reasons for maternal mortality (Cham, 2007). A prospective study conducted in India's small village resulted in 16.5 pregnancy-related morbidities for every maternal death in the village (Datta KK, 1980). Another study from Kerala stated that 34.33 women per 1000 births suffer from severe obstetric complications (Reena, 2015). Study conducted based on NFHS-2 indicated that obstetric complication was high in case of Madhya Pradesh and Bihar, almost a large proportion are suffering from all kinds of morbidities. The main reason behind this was early marriages, birth orders and low standard of living (Jain R. P., 2002). Lack of education and poor economic standards resulted in one-third of the women reporting maternal morbidities in Karnataka (Bhatia, 1995). Different studies conducted at Jharkhand (Kumar, 2004), Maharashtra(Bansod, 2002) and Tamil Nadu(Santhya, 1996) concluded that obstetric morbidity including contraceptive morbidity was high among scheduled caste, scheduled tribes and poor women resident of rural areas. Even today, a large section of Indian women suffers from obstetric complications but still, the severity of the problem remains unknown.

Many studies have been done in India related to obstetric complications (Mukhopadhyay, 2010) (Jungari, 2019) (Gogoi M. \&., 2013) (Gajbhiye, 2021) (Lionel, 2008) (Ahmad, 2021), but there is a scarce of studies focused on the spatial aspect. Geographical information system (GIS), in recent decades, have been popular and helps to know the pattern and trait at a regional level so that interventions can take place accordingly. The potential to relate the social and environmental risks to health outcomes is consistent to reduce adverse maternal health outcomes, by action on social determinants (M. Marmot, 2008). In the case of India, which is considered to be a diverse country with different socio-demographic characteristics in different regions. The regional differences in case of the maternal morbidity conditions are vast in different geographical areas of India (Vora, 2009). The present study assesses the socio-demographic 
characteristics of women with obstetric complications in India and examines the spatial heterogeneity at the district level for different obstetric complications for the year 2015-16 based on National Family Health Survey (NFHS).

\section{Materials And Method}

\section{Data Source}

The study is based on National Family Health Survey-4 (NFHS-4) data conducted in India in the year 2015-16 (National Family Health Survey (NFHS) Mumbai, India, 2015-16). The data is publicly available on request from Demographic Health Survey (DHS) (Demographic and Health Survey). The survey is conducted under the Ministry of Health and Family Welfare (MoHFW), Government of India, who designated the International Institute for Population Sciences (IIPS), India as the nodal agency for the conduct of the survey.

\section{Study place and design}

The study covered 699,686 ever-married women in the age group 15-49 years in India. The sampling design for the survey was a stratified two-stage sample. The urban and rural samples within each State were drawn separately using a multi-stage sampling design.

Sample selection: This study focused on ever-married women aged 15-49 years who have delivered at least once during the five years preceding the survey. The 'women file' of NFHS-4 provides information on the reproductive health of which women who experienced pregnancy complications were used for the study. The women were asked for the most recent birth in the five years preceding the survey if, at any time during the pregnancy, they experienced: swelling of legs, body, or face, convulsions not from fever, difficulty with daylight vision; during the delivery if they experienced breech presentation, prolonged labour, excessive bleeding; or at any time during the two months after the delivery of her most recent child massive vaginal bleeding, very high fever.

\section{Statistical Analysis}

The analysis was performed on Stata 13.1, ArcMap 10.3.1 and Geoda in two phases, firstly obstetric complication was assessed with different background variables using bivariate analysis on Stata 13.1 application. Secondly, spatial estimation of the prevalence of obstetric complications was examined using GeoDa and ArcMap 10.3.1.

Using ArcMap 10.3.1 quantile spatial distribution of the complication was assessed across Indian states. GeoDa was used to generate local indicators of spatial association (LISA) significance and cluster maps and Moran Index. It measured the correlation among neighbouring observations in a pattern and the levels of spatial clustering among neighbouring. Moran's Index assessed the general model of spatial autocorrelation in the region and the overall spatial distribution pattern of the variable on the map including disperses, random or cluster was identified. LISA identifies the spatial clusters for each local data set and the spatial significance of these indicators are assessed. Six categories are classified in the LISA cluster and significant maps and for each category, colour is allocated. LISA for the entire region calculates the separated regions with low or high values of the variable which are surrounded by areas with high or low values and significant levels of each colour.

\section{Results}

Table 1: Demographic Profile of the Study. 


\begin{tabular}{|c|c|c|}
\hline Selected Characteristics & Number & Percent \\
\hline \multicolumn{3}{|c|}{ Socio-Demographic characteristics } \\
\hline \multicolumn{3}{|l|}{ Place of Residence } \\
\hline Urban & 204735 & 29.26 \\
\hline Rural & 494951 & 70.74 \\
\hline \multicolumn{3}{|l|}{ Geographical Regions } \\
\hline North & 140792 & 20.12 \\
\hline Central & 185636 & 26.53 \\
\hline East & 126247 & 18.04 \\
\hline North-East & 98702 & 14.11 \\
\hline West & 56277 & 8.04 \\
\hline South & 92032 & 13.15 \\
\hline \multicolumn{3}{|l|}{ Caste/Tribes } \\
\hline General & 273700 & 41.03 \\
\hline Other Backward Castes & 141428 & 21.20 \\
\hline Scheduled Castes & 124813 & 18.71 \\
\hline Scheduled Tribes & 127133 & 19.06 \\
\hline \multicolumn{3}{|l|}{ Religion } \\
\hline Hindu & 519281 & 74.26 \\
\hline Muslim & 94591 & 13.53 \\
\hline Christian & 52113 & 7.45 \\
\hline Sikh & 15300 & 2.19 \\
\hline Other & 18002 & 2.57 \\
\hline \multicolumn{3}{|l|}{ Highest years of education } \\
\hline No Education & 196,556 & 28.09 \\
\hline Primary & 88,290 & 12.62 \\
\hline Secondary & 334,927 & 47.87 \\
\hline Higher & 79,913 & 11.42 \\
\hline \multicolumn{3}{|l|}{ Wealth Index } \\
\hline Poorest & 133249 & 19.04 \\
\hline Poorer & 149466 & 21.36 \\
\hline Middle & 147168 & 21.03 \\
\hline Richer & 138502 & 19.79 \\
\hline Richest & 131301 & 18.77 \\
\hline \multicolumn{3}{|l|}{ Maternal Characteristics } \\
\hline \multicolumn{3}{|l|}{ Woman's Age } \\
\hline Less than 20years & 124900 & 17.85 \\
\hline age $20 y$ to $34 y$ & 335079 & 47.89 \\
\hline age $35 y$ to $49 y$ & 239707 & 34.26 \\
\hline
\end{tabular}

Page $4 / 13$ 


\begin{tabular}{|c|c|c|}
\hline \multicolumn{3}{|l|}{ Birth Order } \\
\hline First birth order & 93653 & 19.65 \\
\hline Second birth order & 157931 & 33.14 \\
\hline Third birth order & 106867 & 22.42 \\
\hline More than three birth order & 118168 & 24.79 \\
\hline \multicolumn{3}{|l|}{ Number of Antenatal Visits } \\
\hline less than four ANC & 99606 & 52.69 \\
\hline At least four ANC & 89438 & 47.31 \\
\hline
\end{tabular}

Source: NFHS 4, 2015-16 (National Family Health Survey (NFHS) Mumbai, India, 2015-16)

Table 1 talks about the demographic profile of the study and has taken several characteristics into consideration for the same basically divided into two firstly the socio - demographic and the maternal characteristics.

NFHS-4 data (National Family Health Survey (NFHS) Mumbai, India, 2015-16) showed an increase in self-reported obstetric morbidities as compared to NFHS3 (Jain K. G., 2012). The major complication in India was prolonged labour during delivery, experienced by more than two-fifth of the women aged 15 to 49 years. Other major complications experienced were excessive bleeding during delivery, swelling of the legs, body and face during pregnancy and massive vaginal bleeding in the first two months after delivery (Figure 1).

Table 2 presents the results of obstetric complications by socio-economic standing of ever-married women aged 15-49 years. Women residing in the central region reported a high percentage of obstetric complications, almost half the population experience complications during pregnancy, while almost one-fourth suffers from complications during delivery and after pregnancy. Sikh constituted a higher percentage as compared to the other religion. The obstetric complication during pregnancy was high among the educated, while during delivery and after pregnancy complication was high for the illiterate. Women with higher age at first birth showed a higher proportion of complications. Anaemic women showed higher complications during pregnancy and after pregnancy. Also, women who gave to multiple births have a high percentage of obstetric complications.

Table 2: Background factors associated with Obstetric complication among Indian women, NFHS-4: 2015-16, India. 
Background Characteristics Pregnancy Complication

During Pregnancy During Delivery After Pregnancy

Place of Residence

$\begin{array}{llll}\text { Urban } & 42.47 & 21.24 & 25.1 \\ \text { Rural } & 41.95 & 22.31 & 27.97\end{array}$

Geographical Regions

\begin{tabular}{llll} 
North & 41.58 & 21.84 & 27.18 \\
\hline Central & 48.73 & 23.11 & 28.84 \\
\hline East & 41.88 & 23.94 & 27.61 \\
\hline North-East & 33.58 & 18.69 & 16.58 \\
\hline West & 36.46 & 18.81 & 22.96 \\
\hline South & 39.41 & 21.32 & 29.17
\end{tabular}

\section{Caste/Tribes}

\begin{tabular}{llll}
\hline General & 42.63 & 21.26 & 26.23 \\
\hline Other Backward Castes & 42.64 & 22.17 & 27.76 \\
\hline Scheduled Castes & 42.92 & 23.07 & 28.84 \\
\hline Scheduled Tribes & 39.58 & 20.61 & 25.12 \\
\hline
\end{tabular}

\begin{tabular}{llll}
\hline Religion & & & \\
\hline Hindu & 41.59 & 21.87 & 27.15 \\
\hline Muslim & 44.42 & 22.66 & 25.72 \\
\hline Christian & 44.4 & 20.06 & 25.03 \\
\hline Sikh & 48.32 & 24.32 & 52.22 \\
\hline Other & 36.07 & 19.67 & 21.67 \\
\hline
\end{tabular}

Highest years of education

\begin{tabular}{llll}
\hline No Education & 42.2 & 22.50 & 28.64 \\
\hline Primary & 41.91 & 24.88 & 27.68 \\
\hline Secondary & 41.21 & 21.67 & 26.42 \\
\hline Higher & 45.62 & 18.87 & 25.71 \\
\hline
\end{tabular}

Employment Status

\begin{tabular}{llll}
\hline Unemployed & 42.15 & 22.83 & 26.83 \\
\hline Employed & 43.2 & 21.49 & 27.92
\end{tabular}

\begin{tabular}{llll} 
Wealth Index & & & \\
\hline Poorest & 43.87 & 24.1 & 29.57 \\
\hline Poorer & 40.74 & 22.31 & 26.67 \\
\hline Middle & 40.07 & 21.66 & 26.81 \\
\hline Richer & 41.08 & 21.47 & 26.22 \\
\hline Richest & 44.96 & 20.52 & 25.65 \\
\hline
\end{tabular}


Woman's Age

\begin{tabular}{llll}
\hline Less than 20years & 40.84 & 3.66 & 29.14 \\
\hline Age20y to 34y & 42.05 & 31.6 & 27.07 \\
\hline Age 35y to 49y & 43.06 & 17.78 & 26.81 \\
\hline
\end{tabular}

\section{Age at First Birth}

\begin{tabular}{llll}
\hline Under Age 20 & 40.73 & 26.23 & 27.12 \\
\hline Aged $20-29$ & 42.86 & 33.37 & 27.16 \\
\hline Aged 30 and Above & 43.24 & 35.57 & 26.06 \\
\hline
\end{tabular}

\begin{tabular}{llll}
\hline Birth Order & & & \\
\hline First Birth Order & 44.4 & 42.4 & 27.83 \\
\hline Second Birth Order & 39.43 & 29.95 & 26.39 \\
\hline Third Birth Order & 41.15 & 25.24 & 26.21 \\
\hline More than 3 Birth Order & 44.11 & 24.23 & 28.19 \\
\hline
\end{tabular}

\section{Type of Birth}

\begin{tabular}{llll} 
Singleton & 42 & 30.18 & 27.11 \\
\hline Multiple & 53.56 & 33.58 & 28.33
\end{tabular}

\begin{tabular}{llll} 
Anaemia Level & & & \\
\hline Severe & 48.59 & 52.46 & 28.26 \\
\hline Moderate & 42.52 & 53.88 & 28.13 \\
\hline Mild & 41.58 & 53.42 & 27.12 \\
\hline Non-Anaemic & 42.54 & 53.64 & 26.83
\end{tabular}

Figure 2 represents the spatial distribution of obstetric complications across India for 2015-16, during pregnancy the northern and central regions comprising Punjab, Uttar Pradesh and Orissa showed severe complications while Jammu and Kashmir, Haryana, Uttarakhand, Bihar, Madhya Pradesh and Chhattisgarh have high rates of complication. During delivery, severe complication was seen in Rajasthan and Chhattisgarh, while higher rates in the northern region, few parts of southern and western India. After pregnancy complication severe rates was in Punjab, Andhra Pradesh and Telangana, higher rates were in northern and central India.

Figure 3 eflects the local spatial autocorrelation for obstetric complications during pregnancy, which shows that 154 districts of India were identified as highhigh hotspots, of which major districts were from Uttar Pradesh. The low-low hotspot was identified for 112 districts which were mainly from the Southern and North-Eastern regions. Moran Index value of 0.097 shows a random distribution of the prevalence of during pregnancy complications in the neighbourhood.

LISA showed that the high- high local spatial autocorrelation among women during delivery complication was in 147 districts of Punjab and few parts of southern India and its predominant local spatial cluster showed clearly a High-High pattern in comparison with their neighbourhoods. (Figure 4).

Figure 5 shows the distribution for obstetric complications after delivery, which signifies that a region with a high prevalence of after-delivery complications are located into low prevalence areas in the northern parts of India (High-Low pattern). The high-high hotspots were identified for the 117 districts mainly in Uttar Pradesh, Punjab and Andhra Pradesh. While the low-low hotspots were in the northern region comprising of 100 districts.

\section{Discussion}

Studied using Indian National Family and Health Survey, round 4 (2015-16), which is a nationally represented survey data on women's reproductive health.

As already mentioned in the introduction the regional differences in women's morbid condition are vast. The bivariate analysis showed that the regional differences in complications varied. Social characteristics showed the people who practiced Sikhism have a high prevalence of pregnancy complications. Among the caste, the Schedule Caste (SC) has high complications in all the cases. The economic factors determined that the complication was high among employed women. The wealth quantile stated pregnancy complication during pregnancy was highest among the richest, while the complication during delivery and after delivery was high among the poorest quantile. 
The maternal factors identified, pregnancy at a later stage tends to have a high complication during pregnancy, and pregnancy under the age of 20 have a high complication during delivery and after delivery. The women who have multiple births at a time have chances of high pregnancy complications. Also, women who have severe anaemic conditions tend to have high pregnancy complications.

The regions identified under different pregnancy complications were different. The pregnancy complications during pregnancy and after pregnancy were high in the areas of the Northern and Eastern regions of India. While complication during delivery was high in Northern and Southern India. The local spatial autocorrelation showed that the high-high regions of the pregnancy complication were located in the low prevalence regions (high-low).

\section{Limitations Of The Study}

The study has several limitations. Firstly, the study depends on self-reported obstetric morbidities including symptomatic rather than clinical results. As it's on a recall basis the study may be exposed to recall error. Secondly, the study couldn't show the trend which would be more helpful in understating the pattern. The lack of data of particular complications in the previous rounds was the main reason the trend couldn't be presented.

\section{Conclusion}

Despite, several programmes and policies for pregnant women the obstetric complications still exist in several pockets of India. The spatial analysis gives us insights to give special attention to certain regions, the pregnancy complication is one of the main reasons for higher maternal mortality. Sustainable development goal targets to reduce maternal mortality to less than 70 per 100, 000 live births by 2030 . India's maternal mortality currently stands at 113 maternal deaths per 100,000 live births. To achieve the SDG, we need to shift our focus from nationals to state-level policies intervention according to their socio-demographic characteristics. In addition to current policies and schemes, particular customized interventions, region-specific allocation of funds and awareness programs would decrease the obstetric complication prevalence, ensuring better maternal health and reduced maternal mortality.

\section{Declarations}

Ethics approval and consent to participate: N.A.

\section{Consent for publication: N.A.}

Availability of data and materials: National Family Health Survey-4 (NFHS-4) data conducted in India in the year 2015-16 (National Family Health Survey (NFHS) Mumbai, India, 2015-16). The data is publicly available on request from Demographic Health Survey (DHS) (Demographic and Health Survey) https://dhsprogram.com/data/available-datasets.cfm.

\section{Competing interests: N.A.}

\section{Funding: N.A.}

Authors' Contributions: Abstract: Shriya Bajaj

Concept: Shriya Bajaj

Introduction: Shriya Bajaj

Methodology and Data Analysis: Shriya Bajaj

Prepared Tables: Rahul Kumar Jha

Prepared Figures: Shriya Bajaj

Conclusion and Discussion: Shriya Bajaj

Limitations of the study: Shriya Bajaj

Reviewed the manuscript: All the authors.

Acknowledgements: N.A.

\section{References}

1. Ahmad, D. M. (2021). The knowledge of danger signs of obstetric complications among women in rural India: evaluating an integrated microfinance and health literacy program. BMC pregnancy and childbirth,, 21(1), 1-23.

2. Assembly, G. (2015). Sustainable development goals. SDGs Transform Our World, 2030.

3. Bansod, D. (2002). Contraceptive morbidity and quality care in Maharashtra. In Unpublished M. Phil. Seminar Paper, IIPS, Mumbai, (Vol. 10).

4. Bhatia, J. C. (1995). Self-reported symptoms of gynecological morbidity and their treatment in south India. Studies in family planning, $203-216$.

5. Biswas, R. (2016). Maternal Care in India Reveals Gaps Between Urban and Rural, Rich and Poor. 
6. Cham, M. V. (2007). Maternal death in rural Gambia. Global Public Health, 2(4) : 359-372.

7. Datta KK, S. R. (1980). Morbidity pattern amongst rural pregnant women in Alwar, Rajasthan-A cohort study. Health and Population Perspectives and Issues, 3(4), 282-92.

8. Demographic and Health Survey. (n.d.). Retrieved from The DHS Program: https://dhsprogram.com/data/

9. Filippi, V. G. (2010). Effects of severe obstetric complications on women's health and infant mortality in Benin.. Tropical medicine \& international health, 15(6), 733-742.

10. Gajbhiye, R. K. (2021). Clinical presentations, pregnancy complications, and maternal outcomes in pregnant women with COVID-19 and tuberculosis: A retrospective cohort study. International Journal of Gynecology \& Obstetrics.

11. Gogoi, M. \&. (2013). Maternal anaemia, pregnancy complications and birth outcome: evidences from north-east India. Journal of North East India Studies, $3(1), 74-85$.

12. Gogoi, M. U. (2014). Utilization of maternal health care services and reproductive health complications in Assam, India. Journal of Public Health, 22(4), 351-359.

13. Jain, K. G. (2012). Are self reported morbidities deceptive in measuring socio-economic inequalities. The Indian journal of medical research, $136(5)$, 750.

14. Jain, R. P. (2002). Maternal morbidity and utilization of antenatal care services: A study of Madhya Pradesh and Bihar. Population, Health and Development in India.

15. Jungari, S. \&. (2019). What he knows about her and how it affects her? Husband's knowledge of pregnancy complications and maternal health care utilization among tribal population in Maharashtra. India. BMC pregnancy and childbirth, 19(1), 1-12.

16. Kumar, B. (2004). Reproductive morbidity among scheduled tribe women in selected districts of Jharkhand. In Unpublished MPS Seminar Paper, IIPS, Mumbai.

17. Lionel, J. T.-U. (2008). HIV and obstetric complications and fetal outcomes in Vellore, India. Tropical doctor, 38(3), $144-146$.

18. M. Marmot, S. F. (2008). Commision on social determinants of health. Closing the gap in a generation: health equity through action on the social determinants of health. Lancet, 372 (9650), pp. 1661-1669.

19. Maine, D. W. (1997). Guidelines for monitoring the availability and use of obstetric services. United Nations Children's Fund..

20. Mukhopadhyay, P. C. (2010). Hospital-based perinatal outcomes and complications in teenage pregnancy in India. Journal of health, population, and nutrition,, 28(5), 494.

21. National Family Health Survey (NFHS) Mumbai, India. (5015-16). Retrieved from International Institute for Population Sciences; 2006. IIPS and Macro Internationals.: http://rchiips.org/nfhs/nfhs4.shtml

22. Paruk, F. \&. (2001). Severe obstetric morbidity.. Current Opinion in Obstetrics and Gynecology, 13(6), 563-568.

23. Prual, A. B.-C. (2000). Severe maternal morbidity from direct obstetric causes in West Africa: incidence and case fatality rates.. Bulletin of the World Health Organization, 78, 593-602.

24. Quraishi, S. R. (2017). Levels and determinants of maternal morbidity in Sangli, Maharashtra, India: a community based study. International Journal of Community Medicine and Public Health, 4(3), 769.

25. Reena, R. U. (2015). Severe Obstetric Morbidity: Prevalence, Risk Factors and Outcome.. National Journal of Community Medicine, India.

26. Santhya, K. \& (1996). Cultural and behavior factor affecting reproductive morbidity in Southern India.. Paper contributed to Informal Session, 1.

27. Santora, E. (2020). The impact of the safe motherhood initiative from 1987 to 2000. Embryo project encyclopedia.

28. Spiegel, D. A. (2013). World Health Organization global initiative for emergency and essential surgical care: 2011 and beyond. World journal of surgery, 37(7), 1462-1469.

29. SRS. (2020). SPECIAL BULLETIN ON MATERNAL MORTALITY IN INDIA 2016-18. Sample Registration System, Census of India.

30. Vora, K. S. (2009). Maternal health situation in India: a case study. Journal of health, population, and nutrition, $27(2), 184$.

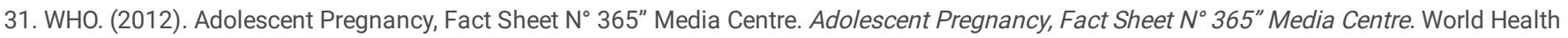
Organisation.

32. WHO. (2019, September 19). World Health Organization. Retrieved from who.int: https://www.who.int/news-room/fact-sheets/detail/maternalmortality\#: :text=The\%20MMR\%20in\%20low\%20income,births\%20in\%20high\%20income\%20countries.\&text=Women $\% 20 \mathrm{in} \% 20 \mathrm{less} \% 20 \mathrm{developed} \% 20 \mathrm{col}$ 33. World Bank. (1996). Improving Women's Health in India.

\section{Figures}




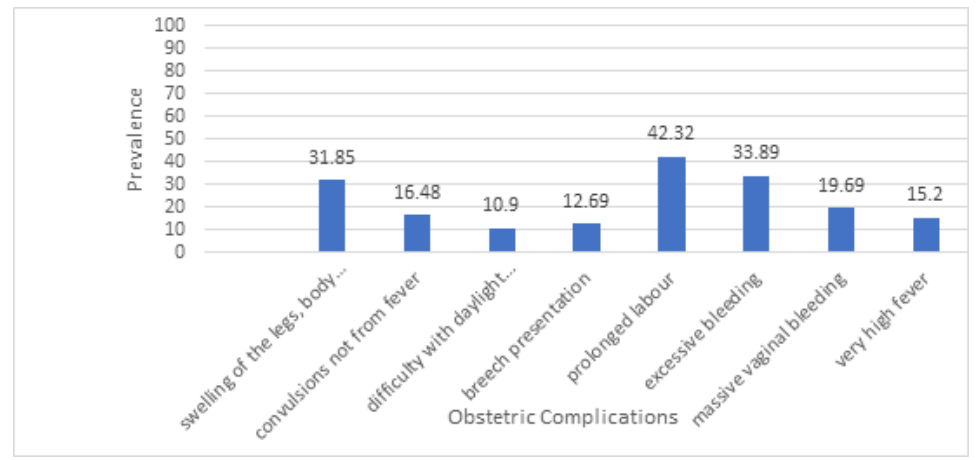

Figure 1

Percentage of women aged 15-49 by type of obstetric problem in India, NFHS:4 (2015-16), India.

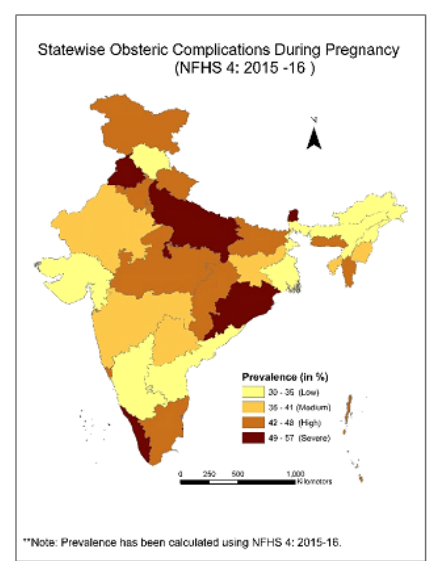

a.During Pregnancy Complication

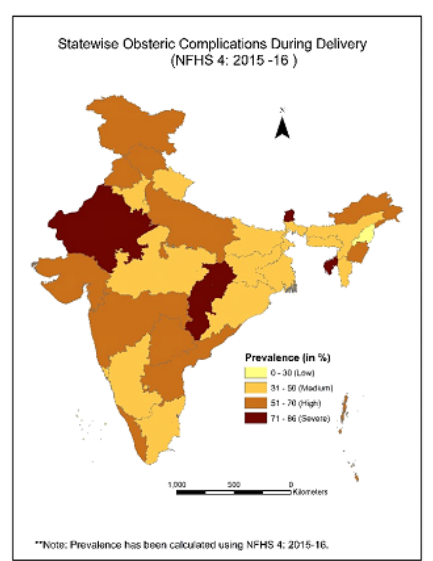

b. During Delivery Complication

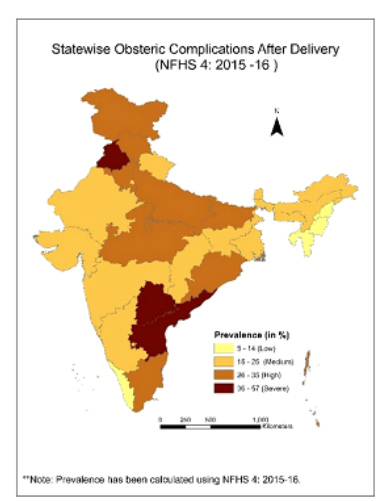

c. After Delivery Complication

\section{Figure 2}

Spatial distribution of prevalence of obstetric complications during pregnancy, delivery and after delivery, NFHS 4: 2015-16, India. 


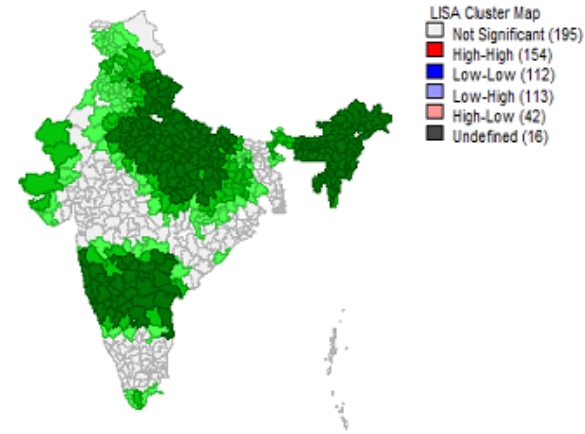

a. LISA Significant Map

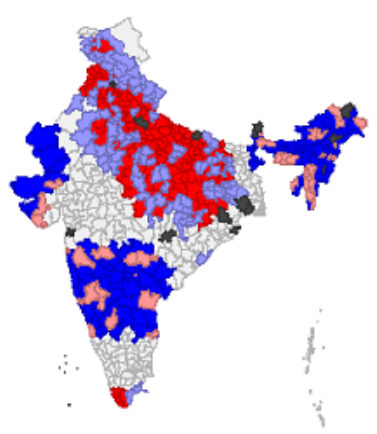

b. LISA Cluster Map

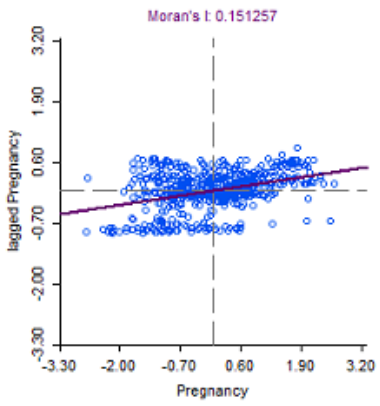

c. Moran Scatter Plot

Figure 3

GeoDa Local Indicator of Spatial Association significant and cluster maps, Moran's Scatter plot of prevalence of obstetric complication during pregnancy (NFHS-4: 2015-16) (*Pregnancy: Women's prevalence of complication during pregnancy). 
LSA Significance Map
Not Significant (233)

$p=0.05$ (82)

$p=0.01(80)$
$p=0.001(221)$

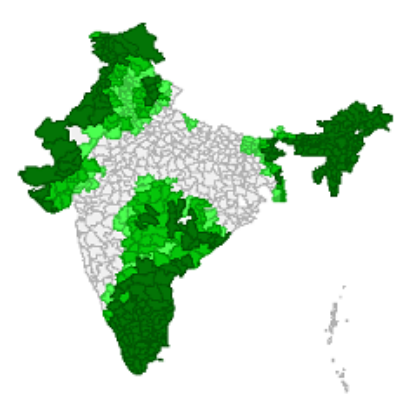

a. LISA Significant Map
LSA Cluster Map
$\square$ Not Significant (233)

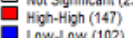

High-Low (35)

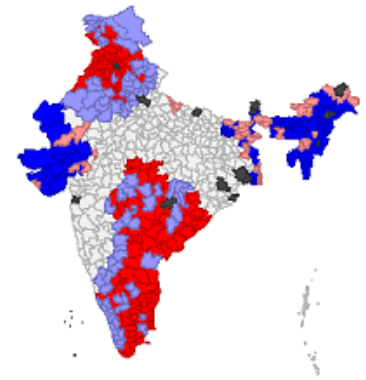

cb. LISA Cluster Map

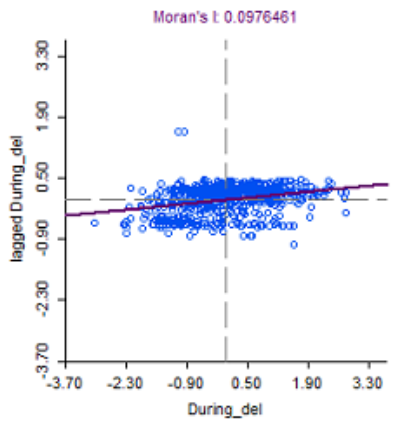

c. Moran Scatter Plot

Figure 4

GeoDa Local Indicator of Spatial Association significant and cluster maps, Moran's Scatter plot of prevalence of obstetric complication during delivery (NFHS4: 2015-16), India (*During_del: Women's prevalence of complication during delivery). 


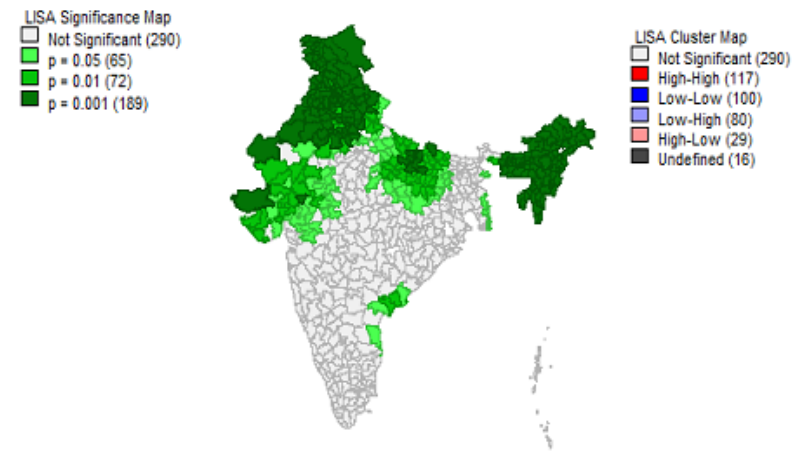

a. LISA Significant Map

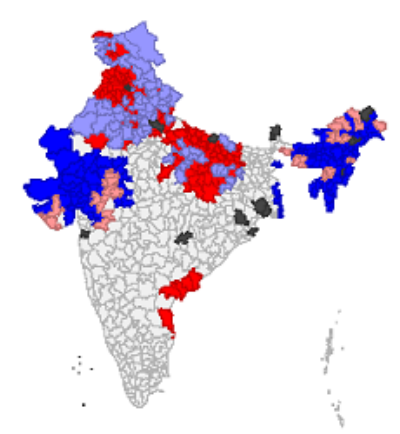

b. LISA Cluster Map

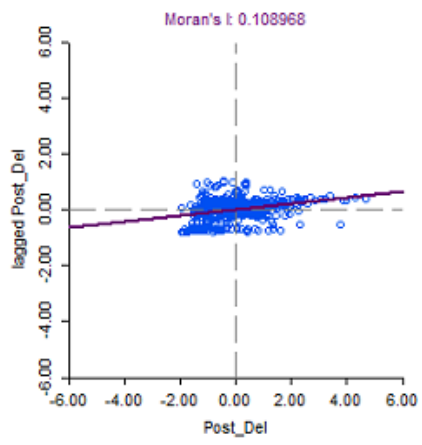

c. Moran Scatter Plot

\section{Figure 5}

GeoDa Local Indicator of Spatial Association significant and cluster maps, Moran's Scatter plot of prevalence of obstetric complication after pregnancy (NFHS-4: 2015-16) (*post_del: Women's prevalence of complication after pregnancy) 